\title{
A LITERATURA INDÍGENA EM SÃO GABRIEL DA CACHOEIRA-AM: DIÁLOGO INTERDISCIPLINAR COM A HISTÓRIA DE OCUPAÇÃO DO ALTO RIO NEGRO.
}

\author{
THE INDIGENOUS LITERATURE IN SÃO GABRIEL DA CACHOEIRA-AM: \\ INTERDISCIPLINARY DIALOGUE WITH THE HISTORY OF OCCUPATION OF THE \\ UPPER RIO NEGRO.
}

\author{
Vera Lucia Teixeira Kauss * \\ verakauss@globo.com \\ Joaquim Humberto Coelho de Oliveira* \\ jhubertoo@uol.com.br \\ Carlos Antonio Pereira da Silva \\ profcp@ig.com.br \\ * Universidade do Grande Rio, Duque de Caixas/RJ, Brasil
}

\begin{abstract}
Resumo
A Literatura Indígena escrita é uma forma de concretização das histórias dos povos nativos que aqui habitam há mais de 500 anos. Ela é, também, o eco das suas vozes contra a omissão em relação aos cuidados com a natureza e contra a desigualdade que vivenciam desde o início da colonização do Brasil.A estreia da literatura escrita pelos indígenas é recente no mercado editorial, mas já marcou presença enquanto instrumento de luta e de ação política na conquista dos direitos que lhes foram tirados pelos colonizadores. Em São Gabriel da Cachoeira, entre lendas das culturas das etnias Tukano, Baniwa, Yanomami, entre muitas outras, lideranças indígenas expandem essas vozes, como na poesia do cacique tukano Manuel Fernandes Moura. Outros escritores indígenas fazem parte desse texto: Graça Graúna, Daniel Munduruku, são exemplos. $\mathrm{Na}$ imagem que descreve os povos e a pluriculturalidade, aparece São Gabriel da Cachoeira, no Amazonas, como um espaço onde convivem os indígenas, os militares, os comerciantes e os imigrantes de forma que garanta a sobrevivência de todos. Este artigo tem o objetivo de dar a conhecer esse lugar através do olhar de um de seus autores que lá vivenciou uma experiência no magistério muito enriquecedora e inesquecível.
\end{abstract}

Palavras-chave: Literatura Indígena, São Gabriel da Cachoeira, História.

\begin{abstract}
Written Indigenous Literature is a way of concretizing the stories of the native peoples who have lived here for more than 500 years. It is also the echo of their voices against the omission in regard to the care for nature and inequality that they have experienced since the beginning of the colonization of Brazil. The publication of the literature is recent in the publishing market, but it has already been present as an instrument of struggle and political action in the conquest of the rights that were taken from the colonizers. Amongst the legends of Tukano, Baniwa, Yanomami, and other ethnic groups, indigenous leaders expand these voices, as in the poetry of the tukano chief Manuel Fernandes Moura, in São Gabriel da Cachoeira. Other indigenous writers are part of this text: Graça Graúna, Daniel Munduruku, are examples. In the image that describes people and pluriculturality, São Gabriel da Cachoeira appears in the Amazon as a space where indigenous people, military, traders and immigrants live in a way that guarantees the survival of all. This article aims to make known this place through the eyes of one of its authors who lived there a very enriching and unforgettable teaching experience.
\end{abstract}

Keywords: Indigenous Literature, São Gabriel da Cachoeira, History. 


\section{INTRODUÇÃO}

Os povos indígenas brasileiros vivenciam a exclusão e a marginalidade desde a chegada do português nessas terras que vieram a formar o Brasil. Eles tiveram seu modo de vida invadido e destruído pelo colonizador e, ao mesmo tempo, foram relegados a viver fora das cidades aqui construídas após 1500, nas florestas. Não se respeitou seus costumes e crenças, suas organizações sociais e políticas foram desestruturadas e, em troca, não lhes foi dado nenhum suporte: nem na saúde, nem na educação, e as políticas públicas que os governos pensavam tinham sempre a intenção assimilacionista, ou seja, integrá-los à sociedade não indígena, levando-os a abandonarem seu modo de ser e estar no mundo.

Desde que começou o contato entre as culturas indígenas e a que foi trazida e imposta pelo conquistador, os povos nativos lutam para manter sua cosmogonia: suas crenças e costumes; enfim, seu modo de ser. A literatura é, hoje, um dos vários instrumentos de luta que esses povos desenvolveram para tentar reaver os direitos que lhes foram tirados com a chegada dos portugueses.

Este artigo tem o objetivo de apresentar, mostrando um pouco do povo que vive em São Gabriel da Cachoeira, no Amazonas, na região conhecida como Cabeça do Cachorro formado pelos povos indígenas da região, militares com suas famílias, os imigrantes, os comerciantes, religiosos e pesquisadores de várias universidades brasileiras e do exterior. Tem também a intenção de, através do poema "Poesia de um guerreiro", escrito pelo cacique Manuel Moura Tukano, apresentar uma face da literatura indígena: uma voz que grita por escrito, as mazelas, a destruição da natureza e dos povos autóctones em geral. Vários autores e estudiosos, muitos deles oriundos dos povos indígenas, têm escrito sobre suas origens, os problemas sociais que enfrentam e sobre a história das suas individualidades coletivas, como diz Stuart Hall (2014) como valor maior para a concretização de suas lutas em prol do respeito pelo passado e pela esperança de um futuro melhor. Alguns desses escritores indígenas serão citados nesse trabalho: Graça Graúna, da etnia Potiguara, é escritora, professora universitária na UFPE e Doutora pela Universidade de São Carlos, UFSCAR, em São Paulo; Daniel Munduruku, que possui o Doutorado em Educação, pela USP e o Pós-Doutorado em Literatura, pela UFSCAR; é escritor, foi professor e, hoje, coordena o Instituto UKA que leva o conhecimentos sobre as Culturas e Literatura Indígenas aos colégios de São Paulo; Gersem José, da etnia Baniwa, natural de São Gabriel da Cachoeira. Todos esses escritores são representantes de uma linguagem de pensamento vinculado ao objeto constituído em suas obras escritas: o índio.

Todo esse trabalho começou com as observações e vivências que tive - Carlos Antônio - quando permaneci um tempo naquelas terras fronteiriças, como professor, e da necessidade que senti de levar ao 
conhecimento de outros a formação cultural de São Gabriel da Cachoeira, que vem sendo apresentada pela História e pela Literatura Indígenas.

\section{A ocupação}

Os primeiros "invasores" das terras indígenas situadas na fronteira com a Colômbia e a Venezuela foram os padres jesuítas, em 1657. Naquele momento, esse espaço era ocupado, em sua maior parte, pelos indígenas da etnia Tarumã. Atualmente, esse povo é considerado extinto. Algum tempo depois, os jesuítas, depois de dominarem a catequese nas colônias portuguesas, foram expulsos pelo Marquês de Pombal, em 1750.

Em 1695, chegam a essa área outras ordens religiosas - como os carmelitas, por exemplo. Em 1760, o governo português, com receio de invasão pelos espanhóis, manda militares para proteger as fronteiras do lugar e, para isso, são construídos diversos fortes, entre eles, o de São Gabriel da Cachoeira. Em 1891, esse forte transforma-se em uma vila e, em 1943, é batizado de Uapés, em homenagem ao rio que banha a região e que é um dos afluentes do Rio Negro. Essa denominação é dada à parte do Rio Amazonas naquela área geográfica em virtude de suas águas apresentarem-se turvas, escuras, seja em virtude das folhas que caem e que se decompõem sobre essas águas, seja em decorrência da característica de acidez do solo.

Apenas em 1965 recebe a denominação definitiva de Município de São Gabriel da Cachoeira e, em 1968, no governo militar, é considerado área de segurança nacional. Por ser assim considerada, os militares começaram a se estabelecer definitivamente na região na década de 70. Nesse momento, acontece a construção do $1^{\mathrm{a}}$ Companhia de Engenharia de Construção do $1^{\mathrm{o}}$ Batalhão de Engenharia de Construção, originário de Caiacó, no Rio Grande do Norte que, junto com empresas civis, auxiliaram na construção da via principal de acesso a outras comunidades, a BR 307, e do $5^{\circ}$ Batalhão de Infantaria de Selva.

A Unidade Militar de Engenharia deixou de existir em 2003, transformando-se em Companhia de Engenharia de Selva, e o Batalhão de Infantaria tornou-se Brigada. Isso aumentou o contingente de militares dessas duas organizações, oferecendo maior segurança na fronteira. Com eles vieram também nordestinos, missionários de várias religiões e a população indígena que se deslocou para o centro da cidade em busca de alimentos e trabalho. O governo federal, como estratégia de Segurança Nacional, criou o projeto Calha Norte e o Sistema de Vigilância da Amazônia (SIVAM).

\section{Construção identitária dos grupos sociais de São Gabriel da Cachoeira}


Não diferente de outros lugares, os agrupamentos sociais são compostos por sujeitos que possuem características individuais que, pós-modernamente, podem se diluir em novas identidades, conforme a necessidade social na realidade do mundo atual. De acordo com Bauman:

Hoje em dia, "individualidade" significa em primeiro lugar a autonomia da pessoa, a qual, por sua vez, é percebida simultaneamente como direito e dever. Antes de qualquer outra coisa, a afirmação "Eu sou um indivíduo" significa que sou responsável por meus méritos e meus fracassos, e que é minha tarefa cultivar os méritos e reparar os fracassos. Como tarefa, a individualidade é produto final de uma transformação societária, disfarçada de descoberta pessoal. (BAUMAN: 2007, pp.30-31)

Esse conceito de individualidade em relação à identidade no contexto social, faz-nos pensar sobre que sujeitos são os ocupantes, na atualidade, desse espaço geográfico e de que forma influenciam a cultura dos povos daquele local. Os religiosos foram os primeiros a marcar território com suas crenças e rezas, que acabaram mescladas aos rituais e costumes dos povos indígenas da região. De acordo com Luan Barros:

No século passado, os índios viram nas missões salesianas uma saída para compreender a cultura "branca" e assim poder ao menos dialogar com estes. As missões, além de levar parte da cultura ocidental até o alto Rio Negro, demonizaram a cultura local, deixando marcas profundas nas comunidades. Os padres tinham uma postura autoritária e intransigente em relação às bases de sua cultura, especialmente a língua e, claro, a religiosidade. (BARROS: 2010, p. 127)

As consequências dessa junção estão presentes, hoje, nas festas religiosas de São João, pois, nelas, podemos ver os índios dançando quadrilha e, ao mesmo tempo, praticando seus rituais de origem. Tudo bem próximo ao que acontece nas festividades religiosas afro-brasileiras.

Além dos religiosos, temos ainda a presença de funcionários públicos federais, principalmente os militares que chegam com suas famílias, trazendo costumes e formas de agir diferentes das que são comuns aos povos locais. Essas pessoas que chegam, em alguns momentos indagam se estão realmente favorecendo uma mistura de conhecimentos entre todos, perguntam-se se estão, de verdade, promovendo de forma positiva a intraculturalização.

Imigrantes de outras regiões do país encontram-se em São Gabriel da Cachoeira. Muitos deles são comerciantes que ali chegaram com a intenção de conseguir retorno financeiro depois de viajarem muito tempo atrás de ouro - nas décadas de 70 e 80 - no Pico da Neblina, um dos pontos mais altos do 
Brasil. Dessa forma, nordestinos e nortistas se estabeleceram na cidade ofertando mercadorias para os que ali permanecem temporariamente ou definitivamente.

Entre esses imigrantes temporários, estão os funcionários de Organizações Não Governamentais (ONGs) que, na maioria, auxiliam o poder público na oferta de uma qualidade de vida melhor àqueles que habitam a região, principalmente os povos indígenas. Infelizmente, algumas dessas instituições são, na verdade, locais administrativos de biopirataria da fauna e da flora da região para países europeus.

Os povos indígenas, primeiros habitantes daquelas terras, portanto, seus donos, são maioria na cidade de São Gabriel da Cachoeira. Eles se deslocam para a cidade em busca de uma melhor condição de vida e passam a conviver com os não indígenas: juntos, eles, através dos mesmos meios sociais, buscam solução para o mesmo problema, que é a sobrevivência.

A FOIRN (Federação das Organizações Indígenas do Rio Negro), criada em 1987, é uma instituição de apoio ao índio. Ela se faz presente em todas as tomadas de decisões que possam ter o habitante natural de São Gabriel da Cachoeira como elemento principal para o desenvolvimento da região e para a manutenção cultural dos povos indígenas. Como nos diz Gersen Luciano, a FOIRN:

(...) tem como principal tarefa a defesa dos direitos e dos interesses dos povos indígenas da região e a busca de modelos alternativos de desenvolvimento que levassem em conta suas culturas, seus valores, seus conhecimentos e suas formas de organização social, política, econômica e religiosa. (LUCIANO: 2008, p. 34)

Essa fundação tem auxiliado, junto com programas de financiamento do governo, a realização de projetos alternativos econômicos que levem os indígenas a usarem suas riquezas naturais para a sobrevivência, não havendo, por isso, necessidade de se deslocarem para a cidade em busca de emprego e alimentos.

Embora se possa observar uma transculturação nos indígenas que se deslocam para a cidade, no caso, São Gabriel da Cachoeira, percebe-se que não há perda em relação à sua identidade original: seus pensamentos, atitudes, seu modo de viver, continuam marcados pelas aprendizagens da convivência com sua etnia mãe. Com o objetivo de não deixar que as identidades individuais e coletivas sejam perdidas, são realizados eventos como o Festribal (Festival das Tribos Indígenas do Alto Rio Negro) em que são oferecidas comidas típicas, danças, rituais e competições esportivas. Esse evento acontece nos primeiros dias de setembro e, nele, os indígenas de todas as etnias locais se reúnem: são cerca de vinte e três povos indígenas do Alto Rio Negro - Tukano, Baniwa, Yanomami, Nheegatu, Baré, Dessana, Tuyuca, entre outros.

Observamos que essas identidades indígenas contemporâneas são oriundas de uma construção forjada por vitórias e fracassos, direitos e deveres, como nos explica Bauman (2007). São, na verdade, o 
resultado do que a sociedade nos impõe como sujeitos consumidores de culturas, de modelos sociais vinculados a comportamentos dominantes e ideológicos.

\section{Cultura de etnias}

A possibilidade de convivência de diversas culturas em um mesmo espaço geográfico é possível e será decorrência da aceitação das diferenças ou da necessidade de sobrevivência. A partir da descentralização de culturas (HALL, 2014) temos a certeza de que aquela que está relacionada a cada grupo não desaparecerá, principalmente quando se busca os meios para a permanência das origens.

Um dos meios de permanência da cultura de origem está na educação escolar e, em São Gabriel da Cachoeira, foi implantado um plano para a valorização das culturas indígenas com a Escola Piloto Tariana. Isso aconteceu devido ao temor de que se perdesse as línguas e os costumes dos povos nativos daquela região. Outra função dessa Escola espera-se que seja trazer às aldeias as tecnologias existentes nas cidades, pois, assim, os povos indígenas passarão a usufruir de informações que tragam acessibilidade aos direitos que muitos outros povos indígenas já conquistaram com relação, principalmente, à saúde e à educação.

A cultura artesanal da arte indígena está presente em São Gabriel da Cachoeira com a presença de suas várias etnias: os Tucanos com seus bancos de madeira; os Dessana e Baniwa com os balaios e raladores de mandioca; os Tuyuca e Baré com artigos de primeira necessidade, ou seja, colheres de madeira, panelas de barro, entre outros).

A questão da ancestralidade, da resistência e da visão do mito como realidade tem levado as comunidades indígenas a reagirem e, com isso, surgirem ações legais que possam trazer a esses povos mais esperança na luta pela reconquista de seus direitos. Segundo Daniel Munduruku:

O que a maioria das pessoas conhece sobre nossa gente indígena é o que está estampado nos livros didáticos, disso já sabemos. O que não se sabe é como definir essa gente que vem sendo chamada por uma alcunha, um apelido, há mais de 500 anos. Esta palavra, carregada de todo sentido pejorativo que um apelido traz, foi capaz de reduzir uma enorme diversidade cultural a um conceito tímido e impreciso capaz de generalizar e empobrecer a experiência de humanidade construída ao longo de 10 mil anos (para não ser arrogante) de conhecimento acumulado. (MUNDURUKU: 2012, p. 15)

A partir de 10 de março de 2008, foi assinada a Lei 11.645 que diz ser obrigatório, em todo o território nacional, o ensino da História e das Culturas Indígenas nas escolas públicas e particulares. 
Com essa Lei, tem-se a intenção de levar ao conhecimento da sociedade as tradições, as formas de espiritualidade, as culturas indígenas que, por tantos séculos, foram colocadas às margens como se nenhum valor tivessem. A tentativa é de acabar com a visão estereotipada do índio vivendo nas matas, de cocar, arco e flecha, caçando e pescando sem ter nenhum conhecimento sobre os fatos que se passam nas cidades.

Juntamente com o ensino das culturas Africanas e Afro-Brasileiras, as culturas dos povos indígenas, finalmente, ganham o direito de se apresentarem como realmente são, mostradas por indígenas. Os povos nativos estão inseridos, de uma forma muito tímida, em uma cultura nacional ainda dominadora e construída pelos colonizadores e, com relação à região do Alto Rio Negro, pelos habitantes que lá chegaram ao longo do século XX. Como nos explica Stuart Hall:

A formação de uma cultura nacional contribuiu para criar padrões de alfabetização universais, generalizou uma única língua vernacular como o meio dominante de comunicação em toda a nação, criou uma cultura homogênea e manteve instituições culturais nacionais, como, por exemplo, um sistema educacional. (HALL: 2014, p.30)

Na região do Alto Rio Negro, como em muitas outras do território brasileiro, é a cultura dominante que decide quais os projetos que devem ser implementados nos espaços geográficos. Ainda existe muita resistência à implantação de mais escolas pilotos que deem ênfase à realidade dos povos indígenas que habitam a região há séculos. Essa atitude decorre da falta de vontade política dos poderes institucionais e, principalmente, do governo federal que, no momento, se omite com relação ao real perigo de se encontrarem, esses povos indígenas, à mercê da presença estrangeira - pessoas gananciosas pelas riquezas vegetais e minerais e por aprenderem a sabedoria dos povos autóctones que habitam a região.

\section{Literatura Indígena}

A professora e escritora Graça Graúna, da etnia Potiguara, é uma guerreira quando se fala em Literatura Indígena. É ela quem afirma que:

Identidades, utopias, cumplicidade, esperança, resistência, deslocamento, transculturação, mito, história, diáspora e outras palavras andantes configuram alguns termos possíveis para designar, a priori, a existência da literatura indígena contemporânea no Brasil. (GRAUNA: 2011, p.01)

As palavras nadantes estão nas citações orais das narrativas de histórias contadas pelos povos indígenas. É na oralidade que a literatura de uma etnia nativa é passada de geração a geração. Desde o 
princípio, os mitos de criação, as lendas, os ensinamentos; enfim, as cosmogonias desses povos são passadas de pai para filho e, nelas, são enaltecidos valores como a coragem, a espiritualidade, o respeito por tudo que existe... Em São Gabriel da Cachoeira, por exemplo, existem lendas que envolvem as praias do Rio Negro que margeiam a cidade. São lendas como a da Praia de Mussum Cuara e da Ilha Adana.

A lenda da Praia de Mussun Cuara diz que o lugar abriga uma cobra adormecida e quem morre afogado ali acaba servindo de alimento para ela. Crendices à parte, essa praia é um ponto de encontro dos moradores e turistas da cidade. A lenda da Ilha Adana diz que Buburi e Curucui são duas corredeiras que representavam dois índios guerreiros que disputavam o amor da linda índia Adana. Como ela havia fugido com Curucui de canoa, Buburi foi atrás do casal e os alcançou no meio do rio. Eles lutaram e todos eles morreram afogados. Os corpos dos dois guerreiros se transformaram nas corredeiras e a bela índia, que também morreu entre seus pretendentes, tornou-se a ilha que recebeu seu nome.

A partir da década de 70 do século XX, o processo de resultado dessa arte passa a se concretizar na escrita: escritores indígenas passam a publicar livros em que contam não apenas os mitos de fundação de seus povos, mas também as lendas e textos que trazem um conhecimento dessas culturas até então desconhecido, pois, até então, esses textos eram produzidos por autores não indígenas que, por mais que estudassem essas culturas, não as vivenciavam como suas de origem.

Atualmente, os textos dos escritores indígenas de diversas etnias procuram mostrar que, para ser um indígena, não é necessário viver na mata, nu, caçando e pescando, com cocar e arco e flecha... Além de mostrar a biodiversidade de seu mundo, os escritores indígenas buscam, em seus textos, mostrar que não são figuras apenas do passado. Que, hoje, eles continuam vivendo e lutando pelo direito à diferença, ou seja, mesmo vivendo nas cidades, eles continuam a ser indígenas e isso é um direito deles.

Para esses escritores, a literatura é mais um instrumento de luta pela garantia do direito de ser e estar no mundo como aprenderam com os seus ancestrais. Mas seus textos não são apenas panfletários, eles possuem características que os colocam como literários. Infelizmente, as editoras ainda não se familiarizaram com essa literatura que retrata nossa origem enquanto brasileiros, elas procuram atender à demanda do mercado capitalista que tem como objetivo o lucro imediato. Mesmo com a dificuldade que encontram para publicar suas obras, muitos desses escritores já possuem uma quantidade considerável de livros publicados.

A literatura indígena propicia o conhecimento da identidade desses povos que, por tantos anos, não tiveram voz, não se mostravam, apenas eram mostrados pelo outro. Nos textos da literatura indígena escrita, eles se dão a conhecer para uma sociedade que os colocou à margem e não se preocupou em 
conhecer, realmente, aqueles povos que já estavam aqui quando chegaram os colonizadores portugueses e que foram colocados sob a homogeneização de uma palavra: índios. Em nossos dias, eles usam a escrita para lutar por seus direitos e, entre esses direitos que lhes foram tirados, o da diversidade étnica que eles lutaram para manter apesar das inúmeras tentativas de aculturação a que foram submetidos pelos não indígenas, pela sociedade envolvente.

O texto literário é uma das formas que os indígenas têm para expressar seu amor à terra, seus sonhos e lutas que auxiliem seus povos a absorver as mudanças que o nosso tempo exige, mas sem perder suas características individuais. Eles também propagam em seus textos a luta pelo acesso aos direitos fundamentais que estão previstos na Constituição do Brasil, que diz em seu artigo 5: “todos são iguais perante a Lei. (CRFB, 1988)

\section{Grito de revolta de um guerreiro: "Lamento nacional de um guerreiro"}

Manuel Fernandes Moura, cacique e liderança do povo Tukano, escreveu uma paródia com a letra do Hino Nacional Brasileiro em um momento de revolta com a indiferença do segmento de governo para com as reivindicações dos povos indígenas. Moura Tukano, como era conhecido, nasceu em São Gabriel da Cachoeira e morreu em 03 de agosto de 2014. Em seu poema, o autor usa a linguagem poética para reagir aos desmandos da política. Em seu texto, ele diz que:

Ouviram do Ipiranga às margens plácidas

Atrás das margens, gritos reprimidos por tortura, Lágrimas de um povo heroico - o brado que não retumba.

O sol da liberdade, em raios contidos

Tem vergonha de brilhar em nossa pátria...

Em seu poema, poucos versos apresentam rima: "És devastada, destruída, humilhada e fragilizada sem amor / Ó antigo colosso, e o teu futuro espelha esse horror". A preocupação do autor foi a de mostrar o Hino Nacional como um grito, não o do Ipiranga, mitificado nos livros de História, mas o de protesto dos povos indígenas marginalizados e massacrados há séculos. Que ele quer é fazer todos ouvirem a voz do guerreiro que luta por seu povo, por todos os povos indígenas brasileiros.

$\mathrm{O}$ autor, na sua representação social, expõe, pela linguagem poética, o seu pensamento enquanto indivíduo que faz parte de um grupo social há muitos anos marginalizado e excluído da sociedade envolvente. Nessa representação, a natureza como elemento desse grupo, também reclama das adversidades sofridas por ele. É pela linguagem subjetiva, mas politizada, que o autor dá voz ao indígena. Como explica Castoriadis: 
Isso porque não há sujeito sem linguagem ou pensamento sem linguagem; e também (do ponto de vista "transcendental" intrínseco) porque, para que o objeto seja, ou seja pensável, ou seja constituído, é preciso que ele se mantenha como "índice de si", que ele se represente "ele próprio", através dos "momentos" (lógicos) de seu ser, de seu serpensado ou de seu ser-constituído. (CATORIADIS: 1985, p. 300)

Entretanto, essa linguagem poética tem o auxílio da História daqueles povos, os dos indígenas do Alto Rio Negro ou de qualquer parte do país, contada pelo viés da religiosidade ou pelo viés da realidade política. De qualquer forma, entre essas duas áreas dos saberes humanos, Literatura e História, há uma linha tênue, em que, como literatura e ideologia, aquelas ciências "se tangenciam, enquanto ambas pressupõem o mesmo vasto campo de experiência subjetiva" (BOSSI: 2013, p. 248) É bem verdade que

A história quer ser objetiva e não pode sê-lo. Quer fazer reviver e só pode reconstruir. Ela quer tornar as coisas contemporâneas, mas ao mesmo tempo tem que reconstituir a distância e a profundidade da lonjura histórica. (LE GOFF: 1996, p. 21)

Essa lonjura é resgatada pela memória que "é um vínculo com o passado sem abrir mão do que se vive no presente" (MUNDURUKU: 2012, p. 17). Essa memória que traz à tona as tradições é a que também faz lembrar toda a destruição causada pelos colonizadores que para cá vieram a partir de 1500 .

A literatura indígena é, hoje, uma realidade e se faz presente em todo o território nacional através de diversos escritores, cuja maioria usa o nome de sua etnia, de seu povo como sobrenome. O pertencimento a seu povo não acaba quando o indígena escritor deixa sua aldeia para morar em uma cidade. É desse novo lócus de enunciação que ele vai lutar para que o seu povo seja visto sem o olhar idealizado ou estereotipado com que eles foram descritos desde o início da colonização.

O poema de autoria do cacique Moura Tukano é um grito dos povos indígenas brasileiros que ficou sufocado por séculos e, hoje, ecoa como um brado de revolta pela desconsideração com que os povos indígenas brasileiros continuam a ser tratados pelos segmentos de governo, de poder da nação brasileira.

\section{A título de finalização...}

É recente a participação de escritores indígenas na literatura escrita brasileira. Na oralidade, a literatura desses povos nunca deixou de existir com toda sua riqueza. Eles buscam, com esses textos, mostrar aos não indígenas como são realmente, sem idealizações e além dos estereótipos que o ser índio carrega desde a chegada do português. A invisibilidade dos povos indígenas é uma das razões para a 
demora do surgimento dos textos escritos: desde o início da formação do Brasil, eles foram excluídos das cidades, colocados às margens da sociedade estruturada a partir do modelo trazido da Europa.

Nesse artigo, é possível observarmos que, pelo recorte da pluriculturalidade de vida dos habitantes de São Gabriel da Cachoeira, no Alto Rio Negro, Amazonas, os povos indígenas não vivem mais isolados da realidade social do Brasil. As suas identidades coletivas também sofrem mudanças em virtude das líquidas identidades (BAUMAN,2007) que cada membro das etnias vem trazendo aos seus grupos.

Entretanto, esses processos de mudanças não levam ao enfraquecimento da luta que travam para readquirir os direitos que lhes foram tirados e, para eles, a literatura é mais um meio de lutar, de se fazer ouvir, conhecer por aqueles que colocaram sobre eles uma capa de invisibilidade, isolando-os nas florestas. Através de seus textos literários fazem ecoar seu grito por justiça. Escritores, como Daniel Munduruku, Kaká Werá Jecupé, Graça Graúna, Yaguarê Yamã, entre muitos outros.

Manuel Fernandes Moura Tukano, que foi um dos fundadores do Movimento Indígena Brasileiro, está entre esses lutadores e, através de sua poesia, fez ouvir o grito dos excluídos, dos que foram colocados às margens da sociedade estruturada pelos colonizadores, que continuam detendo o poder até hoje através de seus representantes.

A literatura indígena acontece em relação direta com a história desses povos: a poesia, o conto, o romance, as lendas e os mitos formadores que passam a acontecer também na escrita característica marcante das culturas ocidentais - dos textos de autores das diversas etnias das regiões brasileiras, que surgem de suas vidas nas aldeias, da infância, da espiritualidade de cada um, de suas lutas e conquistas, do amor à natureza; enfim, de suas vivências tanto nas matas quanto nas cidades.

\section{Bibliografia}

BARROS, Luan. "São Gabriel da Cachoeira (AM) - As margens do Alto Rio Negro". IN: Revista Observatório Digital - 2010. Disponível em: http://www.itaucultural.org.br/bcodemidias/0011516.pdf. Acesso em 10/12/14.

BAUMAN, Zygmunt. Identidades. Rio de Janeiro: Zahar, 2007.

BRASIL. Constituição (1988). Constituição da República Federativa do Brasil. Brasília, DF: Senado 1988. Disponível em www.planalto.gov.br. Acesso em 10/12/14.

CASTORIADIS, Cornelius. A Instituição Imaginária da Sociedade. Rio de Janeiro: Paz e Terra, 1985, p.

GERSEN, José dos Santos Luciano. "Povos indígenas e etnodesenvolvimento no Alto Rio Negro". In: ATHIAS, Renato e PINTO, Regina Pahim, orgs. Estudos Indígenas - Comparações, Interpretações e Políticas. Série Justiça e Desenvolvimento/IFP-FCC. São Paulo: Contexto, 2008. Disponível em: http://www.fcc.org.br/conteudosespeciais. Acesso em 08/12/14. 
GRAÚNA, Graça. "Literatura: Diversidade Étnica e Outras Questões Indígenas”. In: Todas as Musas. Ano 05, número 02, jan-jun 2014. Disponível em: http://www.todasasmusas.org. Acesso em 10/12/14.

Literatura Indígena: desconstruindo estereótipos, repensando preconceitos. Disponível em: <www.dhnet.org.br/direito/militantes. Acesso em 12/12/14.

HALL, Stuart. A identidade cultural na pós-modernidade. Trad. Tomaz T. da Silva e Guacira Lopes Louro. Rio de Janeiro: Ed. Lamparina, 2014.

LE GOFF, Jacques. História e Memória. Trad. Irene Ferreira et al. $4^{\text {a }}$ ed. CAMPINAS: Ed. Da UNICAMP, 1996.

MUNDURUKU, Daniel. "Literatura Indígena e as Novas Tecnologias da Memória". In: Leetra Indígena

- Revista do Laboratório de Linguagens da Universidade Federal de São Carlos. São Carlos-SP: 2012

Recebido em: 08/02/2017

Aceito em: 08/02/2017

Endereço para correspondência:

Nome Vera Lúcia Teixeira Kauss

e-mail:verakauus@globo.com

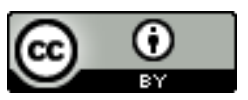

Este obra está licenciada com uma Licença $\underline{\text { Creative }}$

Commons Atribuição 4.0 Internacional. 